\title{
Os desafios e benefícios do trabalho realizado por uma associação de catadores
}

\author{
The challenges and benefits of work carried out by an association of catchers \\ Los retos y beneficios del trabajo realizado por una asociación de receptores
}

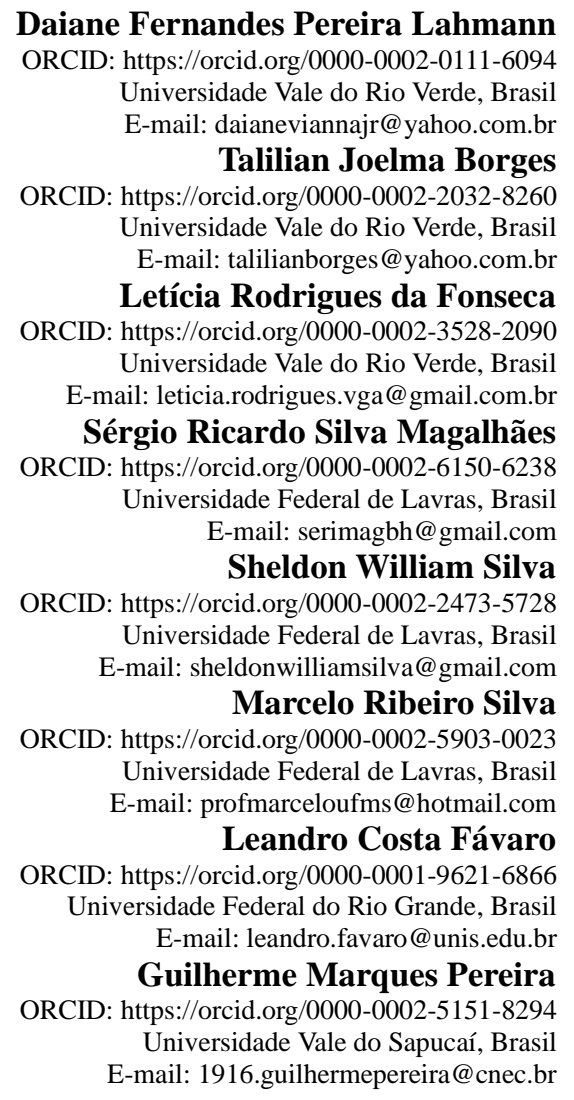

\begin{abstract}
Resumo
O presente estudo objetivou compreender e descrever os desafios e benefícios do trabalho realizado por uma Associação de Catadores localizada na região Sul de Minas Gerais. Para isso, realizou-se um estudo qualitativo básico. Utilizou-se a entrevista semiestruturada como instrumento de coleta de dados e para análise, a técnica de codificação. Entrevistou-se o Presidente-Gestor da Associação e um Associado. Com base nos resultados obtidos, constatou-se que o maior desafio da Associação é garantir a sua subsistência, pois, atualmente, não dispõe de apoio significativo dos Setores Público e Privado e, o pouco apoio que possui, se restringe apenas ao financeiro. Devido à falta de conhecimento e experiência em gestão, os catadores lidam com um gerenciamento precário do seu empreendimento. Constatou-se ainda, que a atividade realizada pelas Associações de Catadores contribui, consideravelmente, para sustentabilidade, seja no âmbito econômico ao possibilitar a reutilização de muitos materiais como matéria-prima, no âmbito ambiental ao diminuir a quantidade de resíduos depositados na natureza e no âmbito social ao proporcionar a um grupo que convive com a desigualdade econômica uma forma de garantir a sua subsistência a partir do seu trabalho.
\end{abstract}

Palavras-chave: Associação de Catadores; Resíduos sólidos; Sustentabilidade.

\section{Abstract}

This study aimed to understand and describe the challenges and benefits of the work carried out by an Association of Waste Pickers located in the southern region of Minas Gerais. For this, a basic qualitative study was carried out. The semi-structured interview was used as an instrument for data collection and for analysis, the coding technique. The President-Manager of the Association and an Associate were interviewed. Based on the results obtained, it was found 
that the biggest challenge for the Association is to ensure its subsistence, as it currently does not have significant support from the Public and Private Sectors and the little support it has is restricted to financial support. Due to the lack of knowledge and experience in management, waste pickers deal with poor management of their business. It was also found that the activity carried out by the Associations of Collectors contributes considerably to sustainability, whether in the economic sphere by enabling the reuse of many materials as raw material, in the environmental sphere by reducing the amount of waste deposited in nature and in the social sphere by providing a group that lives with economic inequality a way to guarantee their livelihood through their work.

Keywords: Collectors Association; Solid waste; Sustainability.

\section{Resumen}

Este estudio tuvo como objetivo comprender y describir los desafíos y beneficios del trabajo realizado por una Asociación de Recicladores ubicada en la región sur de Minas Gerais. Para ello, se realizó un estudio cualitativo básico. La entrevista semiestructurada se utilizó como instrumento para la recolección de datos y para el análisis, la técnica de codificación. Se entrevistó al Presidente-Gerente de la Asociación y a un Asociado. Con base en los resultados obtenidos, se encontró que el mayor desafío de la Asociación es asegurar su subsistencia, ya que actualmente no cuenta con un apoyo significativo de los sectores público y privado y el poco apoyo que tiene se limita al apoyo financiero. Debido a la falta de conocimiento y experiencia en la gestión, los recicladores se enfrentan a una mala gestión de su negocio. También se constató que la actividad que desarrollan las Asociaciones de Recolectores contribuye considerablemente a la sostenibilidad, ya sea en el ámbito económico al posibilitar la reutilización de muchos materiales como materia prima, en el ámbito medioambiental al reducir la cantidad de residuos depositados en la naturaleza y en el ámbito social al brindarle a un colectivo que vive con la desigualdad económica una forma de garantizar su sustento a través de su trabajo.

Palavras clave: Asociación de Coleccionistas; Residuos sólidos; Sustentabilidad.

\section{Introdução}

Os atuais problemas socioambientais conquistaram um espaço de grande relevância entre os assuntos discutidos em nossa sociedade, por serem causados em sua maior parte pela intervenção humana e por ameaçarem não apenas o equilíbrio ecológico do planeta, mas também a existência de diversas formas de vida. No entanto, a natureza continua a ser vista como uma simples fonte de recursos ou um local de depósito de resíduos das atividades humanas. Logo, a nossa atual sociedade privilegia um desenvolvimento que valoriza o capital econômico em vez dos princípios da sustentabilidade (Silva, Reis, \& Amancio, 2011).

Devido a este cenário, a sustentabilidade passou a ser tratada como uma estratégia para atender aos propósitos de crescimento econômico, preservação ambiental e melhoria da qualidade de vida da sociedade de modo simultâneo. São inúmeras as iniciativas voluntárias de grandes corporações voltadas para o desenvolvimento sustentável como forma de atender as três dimensões da sustentabilidade (econômica, ambiental e social). Entretanto, estes esforços ainda não conseguiram satisfazer, de modo igualitário, as demandas existentes nestas três esferas. É importante também destacar a responsabilidade dos cidadãos que estão inseridos em um contexto social que tende a seguir um paradigma antropocêntrico que incentiva o consumo desenfreado. Logo, hábitos e práticas de consumo sustentáveis poderão ocasionar a diminuição da quantidade de bens adquiridos e de resíduos gerados pós-consumo, contribuindo para a preservação ambiental (Barbieri, Vasconcelos, Andreassi, \& Vasconcelos, 2010).

Neste âmbito, os resíduos sólidos se converteram em um dos maiores desafios para sociedade moderna devido à sua geração excessiva e má disposição final. Este tema ganhou importância na discussão global sobre o meio ambiente em países desenvolvidos e subdesenvolvidos desde a Conferência das Nações Unidas - Rio 92, onde se abordou a sua influência no aquecimento global e nas mudanças climáticas (Jacobi, \& Besen, 2011; Babayemi, Ogundiran, \& Osibanjo, 2017; Jia et al., 2018). 
Quanto à sua gestão, a Política Nacional de Resíduos Sólidos (PNRS) publicada em 2010, propõe a responsabilidade compartilhada, com a participação de todos os atores envolvidos no ciclo de vida dos produtos. A gestão de resíduos é de competência e responsabilidade do Estado, do mercado e da sociedade, pois a preservação, a conservação do meio ambiente e a saúde pública, são de interesses públicos (Brasil, 2010; Babayemi, Ogundiran, \& Osibanjo, 2017; Fuss; Vasconcelos Barros, \& Poganietz, 2018).

Entretanto, a sua efetivação ainda requer mecanismos e instrumentos econômico-financeiros que contribuam para a implementação da lei. Ações de educação ambiental realizadas pelo poder público municipal são importantes nesse processo e o serviço prestado por catadores de material reciclável é essencial (Choon, Tan, \& Chong, 2017; Santos et al., 2020).

Com a PNRS, os estados e municípios se viram obrigados a fechar os locais de disposição irregular de resíduos e promover ações de apoio e inclusão social produtiva dos catadores de materiais recicláveis. Para atender a este propósito, buscou-se apoiar as Cooperativas e Associações de Catadores que são instituições criadas com o intuito de gerar renda a partir de um serviço que, ao mesmo tempo em que é demandado pela sociedade, não é abarcado pelo poder público e pela iniciativa privada, e que envolve a coleta, a triagem e venda do material reciclável para reinseri-lo novamente como matéria-prima em sistemas de produção (Asefi \& Lim, 2017; Pardo Martínez \& Piña, 2017).

Diante deste contexto, este estudo se norteou pela seguinte questão de pesquisa: quais são os desafios e benefícios da atividade desempenhada por uma Associação de Catadores para as comunidades em que está inserida? Considerando esta problemática, estabeleceu-se como objetivo principal compreender e descrever os desafios e benefícios do trabalho realizado por uma Associação de Catadores. A escolha da temática se justifica, considerando as imputações da PNRS aos estados e, especificamente, aos municípios, sendo as Cooperativas e Associações de Catadores uma alternativa para o cumprimento de tal política em âmbito municipal.

\section{Revisão Teórica}

\subsection{Desenvolvimento sustentável e gestão de resíduos sólidos}

O conceito sistêmico de desenvolvimento sustentável proposto no Relatório de Brundtland é concebido como aquele que satisfaz as necessidades presentes, sem comprometer a capacidade das gerações futuras de suprir suas próprias necessidades (Ipiranga, Godoy, \& Brunstein, 2011).

Nesse sentido, cabe ao poder público e a coletividade compreender a necessidade de se adotar um desenvolvimento que não esgote os recursos naturais no qual o consumo seja consciente, atendendo assim, os princípios da sustentabilidade que passou a ser compreendida como uma estratégia de desenvolvimento que possibilita a melhoria da qualidade da vida humana $\mathrm{e}$ a minimização simultânea dos danos ambientais. Surge então a visão conexa e holística dos aspectos de desenvolvimento social, crescimento econômico e proteção ambiental, também caracterizados como dimensões da sustentabilidade (social, econômica e ambiental) e que devem ser consideradas no momento do estabelecimento das estratégias de gestão. $\mathrm{O}$ aspecto social envolve habitação, educação, saúde e segurança do capital humano de uma empresa ou sociedade. É caracterizado por ações que busquem o desenvolvimento social da região na qual a empresa atua. $\mathrm{O}$ aspecto ecológico ou ambiental é o capital natural de uma empresa, trata-se da proteção e gestão dos recursos renováveis a fim de amenizar os impactos gerados por sua atividade. $\mathrm{O}$ aspecto econômico envolve a análise da produção, distribuição e consumo de bens e serviços que devem considerar os outros dois aspectos para que o crescimento econômico não influencie, negativamente, o meio ambiente e a sociedade. (Meadows, Meadows \& Randers, 1992; De Assunção Santos, 2019).

No entanto, essa postura sustentável ainda não foi incorporada em sua totalidade no dia a dia, principalmente em países em desenvolvimento como o Brasil, o que acarreta um acúmulo muito grande de resíduos sólidos urbanos (Gouveia, 
2012). Desta forma, esses resíduos sólidos urbanos se tornam um grande desafio na busca pela sustentabilidade integral dos municípios, pois envolve questões econômicas, ambientais e sociais (De Assunção Santos, 2019).

Os resíduos sólidos são caracterizados como todo material, substância, objeto ou bem descartado, resultante de atividades humanas em sociedade e que, devido suas peculiaridades, não podem ser depositados em esgotos ou corpos d’água ou necessitam de tratamento antes do seu descarte (Brasil, 2010). Seu acúmulo sem controle tornou-se um dos principais problemas ambientais, agravado com o crescimento populacional que proporcionou aumento na sua geração, maior custo para a coleta, além de dificuldades para se encontrar locais para a sua disposição final, já que o planeta não consegue absorvê-los em seus ciclos ecológicos (Jacobi \& Basen, 2011; Babayemi et al., 2017; Jia et al.,2018; Fuss et al., 2018).

No Brasil, a discussão a respeito dos resíduos sólidos tornou-se mais evidente nas administrações públicas municipais e nos setores ambientais, em virtude da Lei 12.305 publicada em 2 de agosto de 2010 (Brasil, 2010). A partir dessa lei, determinou-se que em 2 de agosto de 2012, estados e municípios teriam que apresentar Planos de Gestão para ter acesso aos recursos da União destinados à execução da PNRS. Já, em 2014, todos os municípios brasileiros deveriam ter eliminado completamente seus lixões e implantado aterros sanitários ou consorciados para a construção de aterros (Coban, Ertis, \& Cavdaroglu, 2018).

A PNRS estabeleceu prazo até 2020 para que o Brasil tenha toda a estrutura necessária para dar um destino adequado a qualquer resíduo sólido. Dentro da proposta, cabe aos municípios se preocuparem com a localização adequada de aterros sanitários, usinas de compostagem, incineração ou reciclagem, com a operação da limpeza urbana e com a operação dos aterros ou áreas de destinação final (Asefi \& Lim, 2017). Na busca de sua implementação, destaca-se a atuação dos catadores que realizam a coleta seletiva, triagem, classificação, processamento e comercialização dos resíduos reutilizáveis e recicláveis. Mesmo atuando individualmente nas ruas em situações precárias ou coletivamente por meio de cooperativas e associações, contribuem para o aumento da vida útil dos aterros sanitários e diminuição da demanda por recursos naturais, ao reinserirem resíduos nas cadeias produtivas por meio da reciclagem (Simatele, Dlamini, \& Kubanza, 2017; Coban et al., 2018).

Quanto à atividade de coleta seletiva, que não envolve apenas a separação do lixo e reciclagem, podemos descrevê-la como um ciclo que se inicia com a geração do resíduo e finaliza com a inserção do material no ciclo produtivo de uma indústria. Os resíduos gerados por meio do consumo de produtos e serviços são dispostos nas frentes dos domicílios, nos logradouros públicos ou em locais de entrega voluntária. Devido à conscientização sobre a importância da coleta seletiva, alguns cidadãos pré-selecionam estes resíduos e os acomodam em recipientes apropriados para garantir a integridade dos materiais que poderão ser aproveitados. A coleta é realizada, regularmente, por meio de veículos coletores municipais, empresas terceirizadas que transportam estes materiais até aterros sanitários, usinas de incineração, dentre outros locais de descarte. A seleção acontece por meio do recolhimento de resíduos pelos catadores ou pela entrega em pontos específicos. Posteriormente, os resíduos são encaminhados para reciclagem. Neste momento, inicia-se a triagem ou separação do material que poderá ser recuperado para ser reutilizado. Nas Associações de Catadores os materiais que estão em mau estado e/ou que não podem ser reaproveitados são encaminhados para locais de disposição final. Já, os materiais que podem ser reciclados são vendidos para as indústrias recicladoras que os transformam em insumos que podem ser reinseridos nos ciclos de produção (Asefi \& Lim, 2017; Conke \& Nascimento, 2018; Botello-Álvarez et al., 2018; Coban et al., 2018).

\subsection{Cooperativas e associações de catadores}

Com a aprovação da PNRS em 2010, os catadores de material reciclável foram inseridos no gerenciamento integrado dos resíduos sólidos urbanos, pois essa política prevê a inclusão dos catadores no sistema formal de limpeza pública por meio da contratação de organizações que estejam formalmente constituídas em Associações e/ou Cooperativas (Besen et al., 2014; Simatele et al., 2017). Acrescenta-se que este cenário sofreu influência de organizações da sociedade civil como o Movimento 
Nacional dos Catadores de Material Reciclável (MNCR) e de iniciativas que surgiram a partir da realização do Fórum Nacional do Lixo e Cidadania (FNLC) e dos Fóruns Estaduais e Municipais de Lixo e Cidadania (Pereira \& Teixeira, 2011).

Além disso, com o objetivo de aumentar o retorno financeiro obtido por meio de sua atividade, muitos catadores estão optando por se reunir de modo associativo. De acordo com Singer (2002), o que leva indivíduos a se unirem para constituir Cooperativas e Associações é a própria lógica capitalista nas quais se fundamentam, ou seja, no fato de que a existência de um exército reserva de operários possibilita a oferta de mão de obra abundante, o controle de salários e o aumento do lucro capitalista proveniente do meio de produção. Sendo assim, indivíduos marginalizados como aqueles que são estereotipados "catadores de lixo" e que recebem uma pequena remuneração pelo pouco material que conseguem coletar, podem se unir para conseguir um montante maior de material para ser comercializado, o que aumentará a remuneração arrecadada.

A atividade de catação de resíduos recicláveis pode se enquadrar em três categorias principais: carrinheiros; catadores no lixão; cooperativas e associações. Quanto à diferenciação da forma de organização do trabalho das cooperativas e associações em relação às demais, destaca-se: funcionamento simultâneo a um programa de coleta seletiva de resíduos recicláveis; planejamento de ações; metodologia estabelecida para a realização do serviço nas cidades (Gonçalves, 2006). Segundo Baptista (2015), as Associações e Cooperativas de Catadores prestam um serviço público à sociedade, mas necessitam de aparelhos legais, econômicos e institucionais para se manterem e do aporte do poder público para se estruturarem e se organizarem. Neste sentido, os instrumentos legais regulamentadores devem ser adequados a esse tipo de parceria que envolve o mercado, o Estado e a sociedade civil.

Os modelos contemporâneos de Cooperativas de Reciclagem surgiram no início da década de 1990. As formas de parcerias que ocorreram inicialmente entre as Prefeituras e as Organizações de Catadores previam apenas o empréstimo de equipamentos e galpões (Magni, 2011). Atualmente, mais da metade das cidades com programas de coleta seletiva mantém ou apoiam Cooperativas de Catadores para executar a coleta seletiva com equipamentos, galpões de triagem, pagamento de gastos com água e energia elétrica, caminhões, capacitação e auxílio na divulgação e educação ambiental (Cornieri, 2011; Asefi \& Lim, 2017).

Em suma, os catadores, além de encontrarem na coleta de lixo uma maneira de garantir a sua sobrevivência sem se entregar a criminalidade, atuam na defesa de interesses da sociedade e do meio ambiente por meio de sua atividade. A coleta seletiva evita a contaminação do solo, dos lençóis freáticos e nascentes de rios por meio de alguns materiais que levam anos para se decompor. Além disso, a triagem do lixo coletado permite o reaproveitamento de alguns materiais recicláveis pela indústria, preservando os recursos naturais (Pardo Martínez \& Piña, 2017; Botello-Álvarez et al., 2018).

\section{Metodologia}

Optou-se pela realização de um estudo qualitativo básico, que busca compreender os significados atribuídos pelos sujeitos envolvidos com o fenômeno investigado e que ocorre em um determinado contexto social ou organizacional (Merriam, 1998). A pesquisa qualitativa responde perguntas pela investigação de ambientes sociais. Possibilita ao pesquisador compartilhar das compreensões e percepções dos indivíduos que habitam estes ambientes, como interpretar o comportamento das pessoas e os significados que elas atribuem às situações vivenciadas (Berg, 2001).

Para coleta de dados fez-se uso da entrevista semiestruturada, constituída por um conjunto de questões préestabelecidas, que visam auxiliar o pesquisador em seu propósito de compreender os significados que os indivíduos atribuem às questões e situações relacionadas ao fenômeno estudado, pela análise de dados descritivos, coletados em seus discursos (Godoy, 1995). Entrevistou-se dois membros de uma Associação de Catadores de Materiais Recicláveis localizada na região Sul de Minas Gerais, no mês de outubro de 2019. Com o intuito de obter informações de pessoas que apresentassem uma percepção consolidada sobre o ambiente de trabalho desta empresa, foram entrevistados o Presidente da Associação (que 
também é um associado) e um associado que atua na empresa há 6 anos. Além disso, realizou-se uma visita técnica no galpão onde acontece o trabalho de coleta, triagem, seleção, beneficiamento e venda do material reciclável. Neste momento, os entrevistados forneceram informações sobre o funcionamento da Associação.

Para análise dos dados fez-se uso do método de codificação que envolve a identificação e o registro de uma ou mais passagens de texto das entrevistas que irão fazer parte de um quadro geral que, em algum sentido, exemplificarão a mesma ideia teórica e descritiva (Gibbs, 2009).

\subsection{Histórico da associação de catadores em estudo}

A associação investigada neste trabalho localizada no município de Lavras em Minas Gerais, foi fundada em 1997 e não possui fins lucrativos. A microrregião na qual está situada possui uma população estimada de 169.756 habitantes e está, aproximadamente, a $350 \mathrm{~km}$ de Belo Horizonte (Ibge, 2016).

Foi constituída a partir de um grupo de alunos de uma universidade, por meio de trabalhos com uma horta comunitária. Insatisfeitos com a receita decorrente da horta, o grupo migrou para um trabalho de coleta seletiva que deu origem à Associação de Catadores, oficialmente registrada no ano de 2005. Sua missão consiste em coletar, separar e comercializar materiais recicláveis (papéis, plásticos, metais, vidros e óleo de cozinha usado).

Atualmente, desenvolve um trabalho constante de mobilização e conscientização dos moradores dos bairros próximos acerca da importância da coleta seletiva. Junto à Igreja Católica, localizada em seu entrono, buscou adquirir recursos financeiros por meio de rifas e leilões e conseguiu comprar um caminhão e uma Kombi, embora o trabalho tenha se iniciado com uma carroça e um jumento.

\section{Resultados e discussão}

\subsection{Estrutura organizacional da associação de catadores}

De acordo com o Presidente (que também é associado), a Associação de Catadores possui 40 catadores, sendo 36 catadores diretos e 4 catadores individuais. Quanto à diferenciação entre estas categorias, segundo o entrevistado:

Os catadores individuais são aqueles que estão incluídos na Associação e no processo de trabalho, mas não querem cumprir regra e horário, diferente dos catadores diretos. Então, coletam os materiais desses catadores e comercializam junto, trazendo uma melhoria de renda mensal de cada associado que varia entre uma média de $\mathrm{R} \$ 1.200,00$ e $\mathrm{R} \$ 1.100,00$ (Presidente da associação).

Segundo Singer (2002), as associações podem proporcionar aos indivíduos um ambiente de trabalho formal, regido por algumas regras e procedimentos, que possibilita a oferta de mão de obra abundante, o controle de salários e o aumento da remuneração arrecadada. No caso desta pesquisa, constatou-se que os catadores diretos que cumprem as regras estabelecidas pela Associação, são aqueles que conseguem obter a maior renda mensal.

Em relação às atribuições do Presidente da Associação, constatou-se o seguinte depoimento:

$\mathrm{Na}$ verdade, hoje eu trabalho, atuo em quase todas as áreas dentro do empreendimento como catador. Como Presidente da Associação, fico hoje com a parte mais política e burocrática, que seria a questão de correr atrás de empresas, discutir com o poder público, trazer essa discussão mesmo para buscar melhorias para o empreendimento (Presidente da associação).

O grau de instrução do Presidente da Associação é a sexta série do ensino fundamental, e sua faixa etária é de 40 anos. Outro entrevistado (e, também associado) tem 35 anos de idade e o Ensino Fundamental incompleto. Este cenário, de falta de 
instrução acadêmica, mas com grande capacidade de discussão de assuntos de gestão na Associação chamou a atenção dos pesquisadores, pois os conhecimentos, competências e habilidades foram adquiridas com o trabalho diário.

Identificou-se, também, que outros catadores além do Presidente, foram selecionados para assumirem funções administrativas na Associação. A seleção ocorreu a partir da avaliação de comportamentos e conhecimentos práticos adquiridos informalmente em diferentes contextos ao longo da vida, já que não tiveram a oportunidade de adquirir estes conhecimentos específicos por meio da educação formal:

[...] a gente tem um grupo de pessoas aqui que são bons para fazer o operacional, bons para prensar, para coletar. Mas no meio do grupo é possível identificar pessoas que ajudem a gerenciar. Eu consegui visualizar uma das meninas que poderia atuar na parte da tesouraria da Associação, que tinha a expertise para lidar com o dinheiro, muito honesta, e ela é uma associada. E ai, beleza, hoje tudo é associado, a gestão é feita pelos catadores mesmo (Presidente da associação).

Portanto, dentro de suas limitações, esta associação em estudo busca se consolidar como uma organização formal, com processos e normas a serem seguidos e muitos catadores associados apresentam potencial para trabalharem na administração deste empreendimento. Entretanto, conforme Conde e Farias Filho (2016), é evidente a necessidade de investimento em formação para se promover o desenvolvimento profissional deste grupo - o que impactará no desempenho da Associação de Catadores, especialmente nas áreas de gestão financeira, de processos e de pessoas.

\subsection{Os desafios enfrentados no trabalho dos catadores}

De acordo com o Presidente da Associação, um dos desafios enfrentados diariamente está relacionado ao trabalho em equipe. Percebe-se que os catadores possuem entendimentos individuais sobre como gerenciar a organização e que se julgam como corretos. Percebe-se, nesses catadores o que Kolb (1984) pondera como resistência em se aceitar a opinião de seus pares. No entanto, estes entendimentos, na prática, não apresentam os resultados esperados, pois de acordo com o depoimento do Presidente, há dificuldade em se identificar processos organizacionais que possibilitem uma gestão eficaz.

Existe uma grande preocupação com o retorno financeiro, entretanto, pouco se faz para estabelecer um planejamento para que a associação possa obter melhores resultados e progredir:

Uma das maiores dificuldades é realmente o processo coletivo, é o processo de entendimento do grupo, do relacionamento do grupo, dos processos, você entendeu? Um pensa que sabe mais do que o outro [...] uma dificuldade, conseguir medir o que realmente precisa ser feito, de ter esse entendimento, porque a gente vivencia muito dentro dos empreendimentos um processo muito capitalista, então acaba que os processos operacionais eles se perdem um pouco nisso (Presidente da associação).

Acredita-se que este comportamento se deve ao fato dos associados terem voz ativa no processo de tomadas de decisão por meio do voto, o que pode gerar resistência em se aceitar sugestões e questionamentos a respeito dos pontos de vista individuais:

Aqui todo mundo manda, todo mundo tem neh, tem o direito de voto e de voz e muitas vezes as pessoas, elas não conseguem mensurar realmente o processo de trabalho. Muitas das vezes aquilo que é bom para o grupo, um, dois ou três conseguem enxergar e os outros não conseguem. Então isso é uma dificuldade (Presidente da associação).

Uma alternativa para lidar com esta dificuldade seria submeter os catadores às capacitações que tenham como objetivo desenvolver as competências e habilidades necessárias para a gestão do seu negócio; inclusive, a competência de trabalhar em equipe visando uma gestão participativa. Baptista (2015) ressalta que devido a falta de conhecimento e experiência em gestão, os catadores necessitam do apoio de Prefeituras e Organizações do Terceiro Setor para lidar com 
problemas relacionados ao gerenciamento precário de suas organizações, inclusive, frente à burocratização dos procedimentos administrativos que precisam atender.

As exigências referentes à contratação destes empreendimentos, por exemplo, tentam enquadrá-los em modelos incompatíveis com suas realidades, estabelecendo metas e padrões rígidos de produção e prestação de serviços que os catadores não conseguem atender devido a ausência de estrutura, experiência e conhecimento. Sendo assim, os conflitos tendem a se agravar, aumenta-se a precariedade das condições de trabalho e se exclui mais uma vez pessoas com maior grau de vulnerabilidade e menor possibilidade de integração social (Oliveira \& Silva, 2013).

Já, o Associado (entrevistado), apresenta como dificuldade a falta de apoio financeiro da Prefeitura: “[...] Trabalho na Associação por 17 anos e digo que a principal dificuldade é a parte financeira, é que a prefeitura não ajuda mais, dificultando o trabalho (ASSOCIADO). Acredita-se que existe a percepção por parte dos catadores que o único apoio que deveria ser oferecido pela Prefeitura é o financeiro. Os entrevistados, por exemplo, não abordaram a necessidade da Prefeitura promover ações para educação da população em relação ao descarte de materiais -, o que segundo Oliveira e Silva (2013), facilitaria e beneficiaria o trabalho da Associação e a sociedade como um todo.

O Presidente também apresentou como dificuldade o pouco apoio recebido dos Setores Público e Privado - sendo considerada por Marino, Chaves e Santos Junior (2018) coo uma dificuldade comum para associações em geral. Citou, ainda, a diminuição do valor referente à prestação de serviço de coleta seletiva prestado pela Associação ao município:

Tem hoje um recurso, que é um contrato de prestação de serviço com o Município que é de 10 mil, mas esse contrato também foi reduzido, porque era um contrato que gerava em torno de quase 35 mil, 30 mil por mês, e aí reduziu para 10. E hoje a gente recebe $R \$ 9.700,00$, porque tem o valor da nota [...] (Presidente da associação).

A conscientização sobre a importância da coleta seletiva realizada pela associação na comunidade também é comprometida, devido à falta de recursos financeiros para a realização de palestras entre outras atividades:

Nesse processo de trabalho de fazer a coleta, dentro da programação, a gente acabou enxugando algumas atividades, teria o programa de mobilização, conscientização, a palestra nas escolas, isso a gente não tá fazendo, porque não tem recurso (Associado).

A Associação contribui com a limpeza do meio ambiente, ajudando também na educação social da população, conscientizando como reciclar esse tipo de material que para eles são um lixo e para nós uma riqueza, um ouro para gente, trabalhar assim também na parte educativa. A gente tem palestra educativa nas escolas, conscientização das crianças desde pequena. Por isso a ajuda da Prefeitura e das Empresas é muito importante para que a gente consiga realizar este trabalho [...] (Presidente da associação).

Portanto, a ausência de investimentos dos setores público e privado não compromete somente a sustentabilidade no âmbito econômico em relação a reutilização de resíduos em processos produtivos, mas também a sustentabilidade no âmbito ambiental quando ações voltadas para a conscientização acerca da importância da coleta seletiva para o meio ambiente não podem ser realizadas devido à falta de apoio (Choon et al., 2017; Babayemi et al., 2017; Jia et al.,2018; Fuss et al., 2018). Maia et al. (2014), ressaltam que a sociedade precisa compreender a importância do trabalho do catador de material reciclável para a sustentabilidade social, ambiental e econômica. Inclusive, muitas vezes estes trabalhadores não se reconhecem como cidadãos, além de serem marginalizados e possuírem um estilo de vida insalubre que culmina na desvalorização da sua profissão. Sendo assim, é preciso minimizar as dificuldades presentes em seu ofício.

Identificou-se que quando há investimento de instituições privadas o valor é pequeno, sendo utilizado para custear processos operacionais relacionados a atividade da Associação: 
Além da prefeitura, a gente tem a Empresa Y, a Associação tem um contrato com eles no valor de dois mil e seiscentos a cada quatro meses. Foi conseguido ano passado um contrato com o Hospital Z, que é um contrato bem irrisório, mas que é no valor de duzentos reais por mês de combustível, e estão fechando contrato agora também com a Empresa $\mathrm{K}$ nessa mesma modalidade, no valor de R \$200,00 por mês, só que esse valor é em dinheiro para ajudar no processo de coleta (Associado).

Verificou-se que a falta de comprometimento do poder público local resultou em vários problemas na gestão da Associação:

[...] no inicio do ano de 2017, assumi como presidente e a Associação tinha um valor de dinheiro que ela precisaria receber do Município, que era um valor de prestação de serviço. Esse valor não foi pago, era um valor de quase 250 mil. [...] a gente conseguiu receber em torno de 60 mil desse valor e com isso gerou vários problemas da gestão da associação, questões operacionais, combustível, a parte de mecânica, manutenção [...] isso acabou gerando essa dívida de 160 mil, mas nesse período a gente conseguiu reduzir isso em dez meses com o recurso diminuído, a gente conseguiu pagar em média quase 80 mil dessa dívida de 160 (Presidente da associação).

Portanto, a sustentabilidade econômica da Associação implica "em uma gestão eficiente dos recursos e em fluxos regulares de investimento" (Dias, 2009, p. 47).

De acordo com Demajorovic et al. (2014), para que o retorno de materiais recicláveis ocorra em países em desenvolvimento é preciso que haja uma integração entre vários setores, incluindo o público e privado. Este trabalho colaborativo poderia expandir a logística reversa e melhorar as condições de trabalho dos catadores, especialmente quando realizam suas atividades por meio de Associações e Cooperativas. Neste cenário, as empresas poderiam impactar positivamente estas instituições por serem grandes geradoras e compradoras de resíduos, estabelecendo acordos para aumentar a receita dos catadores. Entretanto, para que esta parceria seja possível, é preciso integrá-las na cadeia de suprimentos pois a maior parte dos resíduos pós-consumo inicia seu fluxo reverso pelas mãos dos catadores. Sendo assim, a integração entre esses atores e empresas é fundamental para aumentar a qualidade e a quantidade, contudo, o apoio do setor público e privado é imprescindível para que as Associações e Cooperativas apresentem capacitação adequada, organização e estrutura que permitam a sua integração na cadeia de suprimentos.

\subsection{Os benefícios obtidos com o trabalho realizado pelos catadores}

Buscou-se identificar os principais benefícios obtidos pela Associação por meio de sua atividade. De acordo com o Presidente da Associação, o principal benefício é a fonte de renda gerada por meio do serviço prestado. Atualmente, o retorno financeiro permite o pagamento das despesas da Associação e o lucro obtido é dividido entre os associado. Em suas palavras, “[...] tem em média um retorno que permite cobrir os custos, caminhão, prensa, tudo rodando certinho [...] A renda mensal de cada associado varia entre uma média de R\$1200,00 e R\$1100,00” (Presidente da associação).

Averiguou-se que a Associação contribui com a sociedade ao buscar conscientizar a comunidade na qual está inserida sobre a importância da coleta seletiva para o meio ambiente. Esta conscientização favorece a coleta seletiva devido a mudança de percepção e comportamento em relação a esta atividade que busca se efetivar, levando a comunidade a separar os resíduos domésticos que podem ser reciclados pelos catadores:

A Associação tem o processo de mobilização, que é o primeiro caminho depois da associação constituída, que é a primeira etapa, mobilizar a população, trazer essa ideia, essa conscientização, para que a população possa aderir ao processo de coleta seletiva, separar seu material, para se manter a cidade limpa e a saúde pública. A natureza também agradece, pois muitos materiais demoram muito para desaparecer. [...]depois desse caminho feito e a população aderir a este processo, a gente vai para o processo de coleta. É feita a coleta porta a porta (Associado). 
A efetivação de práticas voltadas para a educação ambiental pelas associações são extremamente significativas a partir do momento que despertam em seus colaboradores e comunidades envolvidos, o interesse pelos problemas ambientais e sociais. Estas práticas podem promover uma conscientização que levará os indivíduos a refletirem sobre suas ações, o que poderá ocasionar uma mudança de valores, hábitos e atitudes (Guimarães, 2016).

Dentre os materiais inseridos no processo da reciclagem da Associação de Catadores, destaca-se como principal o plástico - principalmente, as embalagens do tipo pet -, seguido do papel e também do alumínio. "[...] depois é feito a separação por itens de materiais, cada um na sua classificação: PET branco, PET verde, PAD, PP, PS, papelão, papel branco, papel colorido, caixinha de leite, latinha, metal. Tem o papel branco, tem o papel misto e tem o papelão" (Associado).

Segundo Ribeiro et al. (2014), quanto ao valor monetário dos materiais recicláveis, o grupo de material mais valorizado é aquele no qual se enquadram os metais, principalmente, quando há presença de cobre e baterias automotivas na amostra. Em seguida, estão o alumínio e o plástico, sendo que o papel apresenta o menor valor em relação ao preço por quilo.

Os resíduos obtidos geram em torno de 100 a 110 toneladas de material reciclável que são adquiridos por aparistas (que compram das associações aparas de materiais) ou por indústrias:

Vai para o processo de prensagem, depois para o processo de estocamento e para o processo de comercialização, que é o momento onde a gente pega os fardos já prontos. Coloca no caminhão e ele já vai diretamente para a indústria ou pra algum aparista. Essa coleta é em torno de 100 a 110 toneladas mês de material reciclável (Presidente da associação).

Percebe-se que o trabalho dos catadores está sendo valorizado, principalmente, por grandes indústrias que trabalham com a logística reserva ao adquirir resíduos coletados pelos catadores que podem ser transformados e reinseridos em seu ciclo de produção. Além disso, em algumas situações, estes materiais recicláveis são adquiridos por compradores denominados atravessadores que adquirem os materiais para venderem, posteriormente, para as indústrias: "Hoje a gente trabalha com alguns compradores que são chamados de atravessadores, que fazem o caminho do meio, eles fazem o caminho até a indústria" (Associado).

De acordo com Demajorovic et al. (2014), os catadores autônomos possuem como única opção vender os materiais coletados para pequenos sucateiros sem qualquer condição de barganha, recebendo a menor parcela do que é gerado na cadeia de reciclagem, mesmo sendo aqueles que coletam a maior de quantidade de material. Já, os intermediários na cadeia, no caso desta pesquisa os atravessadores, podem conseguir uma margem de $100 \%$ entre o preço de venda e o que se paga para o catador. Esta diferença não onera a cadeia de reciclagem devido ao valor muito pequeno recebido pelos catadores e que permite manter o preço do material reciclável competitivo, até chegar ao nível mais elevado da cadeia.

Hoje a gente vem fazendo uma discussão de uma forma mais avançada nesse processo de comercialização, porque a Associação ela participa da Rede X, que é uma rede de catadores na região sul e sudoeste, que é um projeto que nasceu através da logística reversa que está envolvido grandes empresas como uma que fabrica alimentos derivados do leite. Então isso vem fortalecendo o grupo de catadores e também a Associação nesse processo de comercialização. Então, hoje, já temos acesso à indústria do PET, já temos acesso à indústria de papelão, estamos tendo algumas conversas com a indústria do PS e também com a indústria de sucata. Isso também tem agregado maior valor no nosso produto (Presidente da associação).

De acordo com Souza, Paula e Souza-Pinto (2012), as associações e cooperativas contribuem no âmbito social e ambiental para os canais reversos de resíduos sólidos pós-consumo, inclusive, segundo os autores, uma das soluções para a questão ambiental nos países em desenvolvimento é a atuação destas instituições que possibilitam a geração de empregos e a participação social. Entretanto, para que isso ocorra, a conscientização será essencial pois é o consumidor que iniciará a cadeia reversa. Logo, é preciso que a população valorize esta atitude para que os propósitos da logística reversa sejam atendidos. 


\section{Considerações Finais}

Frente à teoria revisada, identificou-se a coleta seletiva como a etapa da gestão de resíduos sólidos urbanos que está propriamente relacionada com a situação dos catadores de material reciclável. Assim, de acordo com a PNRS, a meta de acabar com os lixões tem relação com a inclusão dos catadores no sistema formal de limpeza pública. Logo, as prefeituras devem incentivar a coleta seletiva por meio de parcerias com catadores formalmente organizados em associações e/ou cooperativas.

Já, em relação à pesquisa proposta, quanto a estrutura organizacional da Associação de Catadores investigada, identificou-se que, mesmo com pouco conhecimento sobre gestão de empreendimentos, os catadores estão buscando instituir na associação uma estrutura organizacional formal para que as suas atividades sejam melhor organizadas e coordenadas. As funções e atribuições são assumidas pelos próprios catadores. Percebe-se que os referidos buscam planejar e identificar processos e estratégias, a partir de conhecimentos adquiridos por meio da aprendizagem informal. Entretanto, este esforço e a bagagem de conhecimento informal utilizado para gerenciar a associação não estão sendo suficientes para a obtenção de resultados satisfatórios. Esta situação demonstra a importância de se promover a capacitação destes empreendedores para o desenvolvimento das competências, habilidades e atitudes necessárias para a gestão eficaz.

$\mathrm{Na}$ busca de compreender e descrever os desafios e benefícios do trabalho desempenhado pelos catadores, averiguouse que o maior desafio da Associação de Catadores é garantir a sua subsistência, pois não conta com apoio significativo dos setores público e privado e o pouco apoio que recebe, se restringe ao financeiro. Não foram identificadas ações realizadas pelo Poder Público para que a Associação de Catadores possa realizar uma gestão eficaz do seu empreendimento; inclusive, frente à burocratização prevista nos contratos de serviços prestados para as prefeituras. A remuneração oferecida por este serviço, tanto pelo setor público como privado, é pequena e, devido aos atrasos no repasse, o pagamento das despesas e o investimento em ações de conscientização acerca da importância da coleta seletiva realizadas pela própria associação e que beneficiam a sociedade, são comprometidos.

É indiscutível que a colaboração da população seja fundamental para que a coleta seletiva de efetive. Se os resíduos não forem segregados nos locais adequados, o encaminhamento dos materiais potencialmente recicláveis para a indústria se inviabiliza, tornando este processo sem sentido, além de se contribuir para a geração de grandes quantidades de rejeito que são aterrados no lixão. Logo, a conscientização é imprescindível para que esta postura seja adotada. Neste sentido, acatou-se que a Associação de Catadores, por meio de iniciativas próprias, se esforça para conscientizar a comunidade sobre a importância do trabalho executado pelos catadores para o meio ambiente e sociedade.

A temática sobre resíduos sólidos deve ser visualizada como uma questão de interesse público, com múltiplas faces, que envolve aspectos técnico-operacionais, políticos, institucionais, econômicos, ambientais e sociais. Quanto aos aspectos econômicos e ambientais, muitos são os investimentos realizados por instituições públicas e privadas na busca pela sustentabilidade sob o ponto de vista econômico por meio da reutilização dos seus resíduos, mas pouco se preocupa em entender como os resíduos de suas atividades acarretam prejuízos para a natureza e, consequentemente, para a sociedade.

Desta forma, quanto aos benefícios do trabalho desempenhado pela Associação de Catadores, identificou-se que a sua atividade favorece a sustentabilidade, seja no âmbito econômico ao possibilitar a reutilização de muitos materiais, diminuindo assim os custos das indústrias com matéria prima em seus ciclos de produção, seja no âmbito ambiental ao diminuir a quantidade de resíduos depositados na natureza e no âmbito social ao proporcionar a um grupo que convive com a desigualdade econômica, uma forma de garantir a sua subsistência a partir do seu trabalho.

Acredita-se, então, que a inserção destas associações e cooperativas na cadeia de suprimentos poderia ser uma alternativa para aumentar a renda e a qualidade do trabalho prestado por estas instituições, desde que recebem o apoio necessário (capacitação, estrutura física, entre outros) para tal. Assim, espera-se que este estudo contribua para evidenciar a importância do trabalho desempenhado pelos catadores bem como, possa sensibilizar o poder público e a iniciativa privada 
com o intuito de obter maior apoio para este grupo social. Ressalta-se que durante este estudo, os pesquisadores tiveram dificuldade para coletar os dados necessários devido ao trabalho exaustivo dos catadores que os impede de se dedicar à outras atividades. Recomenda-se ainda, que novas investigações com o mesmo propósito sejam realizadas em outras Associações com o intuito de validar os resultados desta pesquisa ou complementá-los.

\section{Referências}

Asefi, H., \& Lim, S. (2017). A novel multi-dimensional modeling approach to integrated municipal solid waste management. Journal of Cleaner Production. $166(1), 1131-1143$.

Babayemi, J. O., Ogundiran, M. B., \& Osibanjo, O. (2017). Current Levels and Management of Solid Wastes in Nigeria. Environmental. Quality Management, 26 (1), 29-53.

Baptista, V. F. (2015) As políticas públicas de coleta seletiva no município do Rio de Janeiro: onde e como estão as cooperativas de catadores de materiais recicláveis? Revista de Administração Pública, 49 (1), 141-164.

Barbieri, J. C, Vasconcelos, I. F. G, Andreassi, T, \& Vasconcelos, F. C. (2010). Inovação e sustentabilidade: novos modelos e proposições. RAE-Revista de Administração de Empresas. 50 (2), p. 146-154.

Berg, B. L. (2001). Qualitative Research Methods for the social sciences. Allyn \& Bacon.

Besen, G. R. et al. (2014) Coleta seletiva na Região Metropolitana de São Paulo: impactos da Política Nacional de Resíduos Sólidos. Ambiente \& Sociedade. 17 (3), 259-278.

Botello-Álvarez, J. E., Rivas-García, P., Fausto-Castro, L., Estrada-Baltazar, A., \& Gomez-Gonzalez, R. (2018). Informal collection, recycling and export of valuable waste as transcendent factor in the municipal solid waste management: A Latin-American reality. Journal of Cleaner Production. 182 (1), $485-495$.

Brasil. (2010) Política Nacional de Resíduos Sólidos. Lei no 12.305, de 02 de agosto de 2010. Institui a Política Nacional de Resíduos Sólidos; altera a Lei n 9.605, de 12 de fevereiro de 1998; e dá outras providências. Brasília/DF: Diário Oficial da União.

Choon, S., Tan, S., \& Chong, L. (2017) The perception of households about solid waste management issues in Malaysia. Environment, Development \& Sustainability. 19 (1), 1685-1700.

Coban, A., Ertis, I. F., \& Cavdaroglu, N. A. (2018). Municipal solid waste management via multi-criteria decision making methods: A case study in Istanbul, Turkey. Journal of Cleaner Production, 180 (1), 159-167.

Conde, R. de N. C., \& Farias, M. C., F. (2016). Relações informais influenciadas pela estrutura formal: Uma análise de redes sociais de gestores. Revista de Ciências da Administração. 18 (46), 68-80.

Collis, J., \& Hussey, R. (2005). Pesquisa em administração: um guia prático para alunos de graduação e pós-graduação. (2a ed.), Bookmman.

Conke, L. S., \& Nascimento, E. P. (2018) A coleta seletiva nas pesquisas brasileiras: uma avaliação metodológica. Revista Brasileira de Gestão Urbana. 10 (1), 199-212.

Cornieri, M. G. (2011). Programa de municipal de coleta seletiva de resíduos sólidos urbanos em Santo André/SP: um estudo a partir do ciclo da política (policy cicle). Dissertação (Mestrado em Ciência Ambiental) - Universidade de São Paulo, São Paulo.

De Assunção Santos, G. M. (2019) Economia circular como política governamental de gestão de resíduos sólidos: Implicações de sua Implementação no Brasil. Episteme Transversalis. 10 (1), 54-68.

Demajorovic. J., Caires, E. F., Silva, L. N., \& Silva, M. J. C. (2014). Integrando empresas e cooperativas de catadores em fluxos reversos de resíduos sólidos pós-consumo: O caso Vira-Lata. Cadernos EBAPE.BR. 12 (1), 513-532.

Dias, S. M. (2009). Trajetórias e memórias dos fóruns lixo e cidadania no Brasil: experimentos singulares de justiça social e governança participativa. Tese (Doutorado em Ciência Política) - Universidade Federal de Minas Gerais, Belo Horizonte.

Fuss, M., Vasconcelos Barros, R. T., \& Poganietz, W. (2018). Designing a framework for municipal solid waste management towards sustainability in emerging economy countries: An application to a case study in Belo Horizonte (Brazil). Journal of Cleaner Production. 178 (1), $655-664$.

Gibbs, G. (2009). Análise de Dados Qualitativos. Artmed.

Godoy, A. S. (1995) A pesquisa qualitativa: tipos fundamentais. Revista de Administração de Empresas. 3(35), 20-29.

Gonçalves, M. A. (2006). O trabalho no lixo. Tese (Doutorado em Geografia) - Universidade Estadual Paulista, Presidente Prudente.

Gouveia, N. (2012). Resíduos sólidos urbanos: impactos socioambientais e perspectiva de manejo sustentável com inclusão social. Ciênc. Saúde Coletiva. 17 (6), 1503-1510.

Guimarães, M. (2016). Por uma educação ambiental crítica na sociedade atual. Revista Margens Interdisciplinar. 7 (9), $11-22$.

Ibge. (2016) Instituto Brasileiro de Geografia e Estatística. Indicadores de Desenvolvimento Sustentável. 
Ipiranga, A. S. R., Godoy, A. S., \& Brunstein, J. (2011). Introdução. Rev. Adm. Mackenzie (Online). 12 (3), 13-20.

Jacobi, P. R., \& Besen, G. R. (2011). Gestão de resíduos sólidos em São Paulo: desafios da sustentabilidade. Estudos Avançados. 25 (71), $135-158$.

Jia, X., et al.(2018). Pinch analysis of GHG mitigation strategies for municipal solid waste management: A case study on Qingdao City. Journal of Cleaner Production. 174 (1), 933-944.

Kolb, D. (1984) Experiential learning: experience as the source of learning and development. Prentice Hall.

Magni, A. A. C. (2011). Cooperativas de catadores de resíduos sólidos urbanos: perspectivas de sustentabilidade. Dissertação (Mestrado em Saúde Pública) Universidade de São Paulo, São Paulo.

Maia, H. J. L., et al., (2014) Educação ambiental: instrumento de mudança de percepção ambiental de catadores de materiais recicláveis organizados em associação. Revista Monografias Ambientais. 13 (13), 2797-2806.

Marino, A. L., Chaves, G.L. D., \& Santos junior, J. L. D. (2018). Do Brazilian municipalities have the technical capacity to implement solid waste management at the local level? Journal of Cleaner Production. 188 (4), 378-386.

Meadows, D., \& Meadows, D., \& Randers, J. (1992). Más allá de los límites del crecimiento. Aguilar.

Merriam, S. B. (1998). Qualitative research and case study applications in education. Jossey-Bass.

Oliveira, F. G., \& Silva, C. M. (2013). Participação dos catadores de materiais recicláveis na política nacional de resíduos sólidos e seus desafios. Congresso Latino-americano de Estudos do Trabalho.

Pardo Martínez, C., \& Piña, W. (2017) Solid waste management in Bogotá: the role of recycling associations as investigated through SWOT analysis. Environment, Development \& Sustainability. 19 (1), 1067-1086.

Pereira, M. C. G., \& Teixeira, M. A. C. (2011) The inclusion of collectors in selective recyclable waste programs: from the local to the national agenda. Cadernos EBAPE. 9 (3), 895-913

Ribeiro, L. C. de S., et al. (2014). Aspectos econômicos e ambientais da reciclagem: um estudo exploratório nas cooperativas de catadores de material reciclável do Estado do Rio de Janeiro. Nova Economia. 24 (1), 191-214.

Santos, P. da C., et al. (2020). Generation of urban solid waste: application of a sustainability indicator in a municipality of the Alagoas semi-arid. Research, Society and Development. 9 (8), 1-15

Silva, S. S., Reis, R. P., \& Amâncio, R. (2011). Paradigmas ambientais nos relatos de sustentabilidade de organizações do setor de energia elétrica. Rev. Adm. Mackenzie. 12 (3), 146-176.

Simatele, D. M., Dlamini, S., \& Kubanza, N. S. (2017) From informality to formality: Perspectives on the challenges of integrating solid waste management into the urban development and planning policy in Johannesburg, South Africa. Habitat International. 63 (1), 122-130.

Singer, P. (2002). Introdução à economia solidária. Fundação Perseu Abramo.

Souza, M. T. S., Paula, M. B., \& Souza-Pinto, H. (2012). O papel das cooperativas nos canais reversos de pós-consumo. Revista de Administração de Empresas, 52 (2), 246-262. 